\title{
Rádio Comunitária, participação e cidadania: a Rádio Jornal FM
}

Marcelo de Oliveira Volpato

\section{Resumo:}

A participação social nos meios de comunicação requer investigação haja vista a ligação desta com a promoção da cidadania, principalmente em meio a processos midiáticos excludentes e autoritários. Desta forma, apresentamos as principais configurações de uma rádio comunitária, de conceitos de participação, cidadania e apresentamos - ainda que preliminarmente - as configurações da Rádio Jornal FM. Baseando-se em pesquisa bibliográfica e documental, entrevistas e observação assistemática de conteúdo, o estudo buscou levantar elementos para compreender os espaços destinados ao desenvolvimento da cidadania e como se dá a participação do(s) público(s) nesta emissora. As observações apontam que estes meios configuram-se como espaço propício à participação e ao exercício da cidadania, entretanto, devido a comprometimentos políticos, econômicos e limitações tecnológicas e profissionais estes espaços tornam-se cada vez mais escassos.

\section{Palavras Chave:}

Rádio Comunitária; Participação Popular; Cidadania.

\section{Abstract:}

The popular participation in the media requires research due the connection of this with the promotion of citizenship. In this case, we present the main characteristics of community radio station, concepts of popular participation, citizenship and present - though preliminary - the configurations of "Jornal FM" radio station. The paper is based on bibliographic research, interviews and non-systematic observation of contents, and aims understand the spaces for the development of citizenship and the kind of popular participation in this radio station. The main results evidences that the community media constitutes a favorable space to popular participation and to the citizenship promotion, however, due to political interests and economic, professional and technological limitations these citizenship spaces become increasingly scarce.

\section{Keywords:}

Community Radio Stations; Popular Participation; Citizenship.

\section{Introdução}

Este texto procura, de forma preliminar, descrever as configurações da Rádio Jornal FM - rádio comunitária regida pela Lei 9.612/98 - e tenta identificar os espaços cidadãos nestes veículos. Consideramos que a relação entre participação na comunicação e a questão da cidadania dá-se de forma diretamente proporcional, desta forma, quanto maior a participação popular nos veículos, maior a possibilidade de espaços destinados ao exercício da cidadania. Procuramos então, apreender como se dá a participação popular na emissora. 
Como metodologia, parte-se de pesquisa bibliográfica e documental, entrevistas e observação assistemática do conteúdo da programação e procura-se levantar elementos para compreender os espaços e os mecanismos destinados à promoção da participação popular.

\section{Rádio comunitária}

Faz-se necessário discutir as diferentes nuances da Rádio Comunitária uma vez que existem diversos tipos de emissoras de rádio de baixa potência com finalidades diferentes, entretanto, todas são comumente chamadas de comunitárias.

Com o objetivo de esclarecer esta diversidade, Peruzzo (1998: 9) agrupa as rádios comunitárias em cinco tipos: a) as eminentemente comunitárias; b) as que estão sob controle de algumas pessoas; c) as comerciais; d) as de cunho político-eleitoral; e) as de cunho religioso.

Sabemos que todos estes tipos de rádios comunitárias prestam relevantes serviços às suas comunidades, entretanto, é preciso ressaltar que as emissoras que em maior escala promovem a cidadania, desenvolvendo processos educativos e participativos, são as eminentemente comunitárias.

Entendemos que "cidadania" relaciona-se diretamente ao processo histórico-social e pode, então, ser compreendida de diversas maneiras. Assim, relaciona-se ao direito de pertencer a uma nação, igualdade perante a lei, direito à liberdade de acesso à informação, direito à comunicação, etc(2) (PERUZZO, 2002: 78-9). Salienta-se que as pessoas, ao exercerem as funções de um veículo de comunicação, além de desenvolverem diversas capacidades como ampliar seus conhecimentos técnicos, aprender a falar em público, etc, ampliam a consciência do direito de ter direito.

O direito de acesso do cidadão aos meios de comunicação como produtor, emissor e gestor por si só, a nosso ver, caracterizaria o exercício da cidadania em sua dimensão cultural, entretanto, a mídia comunitária, além disso, promove a conscientização da população sobre os seus direitos(3).

Este tipo de emissora se constitui como comunicação contra-hegemônica porque veicula um conteúdo diferente da grande mídia, baseado na pluralidade das vozes da comunidade. Difere-se do conteúdo da grande mídia porque contribui "não apenas para democratizar o diálogo, mas principalmente para reduzir visões preconcebidas e preconceituosas sobre os mais diversificados grupos humanos e propostas" (PAIVA, 2007: 141).

Ser uma rádio comunitária não significa se contrapor à produção de qualidade, mas sim promover de fato uma comunicação dialógica e bidirecional, ou seja, onde o receptor torna-se emissor e vice-versa, onde as manifestações político-sócio-culturais da comunidade em que está inserida tenham visibilidade.

Este espaço de acesso aos meios de comunicação pelas comunidades é assegurado pela Lei 9.612/98 que, apesar de suas limitações, estabelece a concessão do serviço de radiodifusão comunitária à fundações e associações comunitárias sem fins lucrativos com sede no local de prestação de serviço. Quanto à "não ter fins lucrativos", entendemos que a emissora não deve destinar os lucros aos seus donos - mesmo porque uma rádio comunitária não tem dono.

Compreendemos ser necessário uma fonte de renda para que a emissora possa desenvolver um trabalho responsável e de qualidade junto à comunidade. Para isso, acreditamos ser possível uma mobilização da própria comunidade, que poderá atuar de diversas formas, seja através de apoios culturais, através de cotas, como associados, enfim, através do trabalho e da movimentação da própria comunidade. 
Importante destacar que, em alguns casos, alguns poucos resolvem privatizar a rádio comunitária para seus próprios benefícios. Estes "coronéis da mídia", promotores de uma comunicação vertical, impositiva e monológica monopolizam aquilo que seria um dos maiores avanços no acesso aos meios de comunicação do Brasil. Além de não possibilitarem o acesso da comunidade ao meio de comunicação e, por consequiência, não darem visibilidade às suas manifestações, reproduzem os conteúdos dos grandes meios de comunicação.

Entretanto, como dissemos, referimo-nos aqui às rádios que atuam como um espaço plural, aberto à participação da comunidade, autogerida pelas entidades representativas da comunidade, autônomas em relação ao governo, grande mídia, partidos políticos e religioso(4).

Quanto aos níveis de participação na mídia comunitária, urge destacar a importância de se atingir níveis mais efetivos de participação popular. Para uma mídia eminentemente comunitária espera-se não apenas que se dê voz à população, mas sim que a comunidade esteja inserida e mobilizada neste processo de "fazer comunicação", inclusive na gestão da emissora. A maioria dos media apresenta baixos níveis de participação como em entrevistas, depoimentos; poucos casos apresentam participação na produção das mensagens; raros casos apresentam participação no planejamento e gestão dos meios. Ressaltamos, contudo, que somente níveis ampliados de participação é que promovem processos de educação e de promoção da cidadania.

Em relação aos conteúdos, a mídia comunitária os apresenta de forma diferente das outras mídias. Segundo Peruzzo,

[...] os conteúdos dizem respeito às necessidades, problemáticas, artes, cultura e outros temas de interesse local, como por exemplo: notícias sobre as atividades de grupos populares organizados, esclarecimentos visando afastar crianças do tráfico de drogas, campanhas contra a discriminação da mulher e das raças, dicas de saúde, informações sobre prevenção de doenças, reivindicações de serviços públicos de uso coletivo e outras informações de utilidade pública (PERUZZO, 2007: 149).

Como se percebe, os conteúdos da mídia eminentemente comunitária também se diferenciam dos apresentados pela grande mídia. Enquanto os primeiros veiculam informações relacionadas àquela determinada comunidade, como explicitado acima, a grande mídia, por atingir públicos maiores, apresenta informações mais gerais como catástrofes, crimes cometidos, esporte nacional e internacional, escândalos no governo estadual ou federal, etc.

Patrick Alumuku e Robert White (2005: 57-8) trazem apontamentos sobre as características de rádios comunitárias da África. As emissoras de Gana, por exemplo, apresentam diversas características parecidas com as brasileiras eminentemente comunitárias como as de produzir programas educativos, procurar alertar a comunidade sobre os principais problemas locais, abordar a questão da violência, saúde, exclusão. Entretanto, algumas contribuições para o caso brasileiro podem ser observadas, como ser dirigida por um pequeno quadro assalariado de pessoas experientes em desenvolvimento e educação comunitários e que atuem como incentivadores da participação da comunidade, angariar apoio através de várias fontes: pagamento de anúncios, publicidade, campanhas de arrecadação de fundos, subvenção de agências estrangeiras para o desenvolvimento.

Sabemos que no Brasil as rádios eminentemente comunitárias enfrentam diversos problemas quanto à escassez de recursos financeiros, uma vez que a legislação brasileira permite apenas a veiculação de apoios culturais. Seguindo o mesmo raciocínio de López Vigil (2004), salientamos a necessidade de a mídia comunitária ter o direito de se estabelecer como instituição/associação e arrecadar recursos de 
forma eficaz. Indiscutivelmente arrecadar recursos não significa privatizar os benefícios arrecadados, isto é, destinar o lucro a algumas poucas pessoas, mas sim, à melhoria e ao aperfeiçoamento da emissora.

No mesmo sentido parece acenar Gláucia Conceição Ventura (2004: 97) quando compara os principais aspectos das rádios comunitárias do Brasil e Canadá. Segundo ela, no Canadá existem rádios "financiadas por doações provenientes de sua audiência, por organismos de desenvolvimento internacional, por meio de publicidade e por parte dos governos" (VENTURA, loc. cit.). A autora ainda afirma que algumas emissoras canadenses "pertencem a organizações sem fins lucrativos ou cooperativas cujos membros constituem sua própria audiência. Outras pertencem a estudantes, universidades, municípios, igrejas ou sindicatos" (Ibidem: 97).

Uma outra disparidade considerável entre os dois países é quanto à autorização pela legislação canadense do funcionamento das emissoras comunitárias tanto em amplitude modulada (AM) como em freqüência modulada (FM), enquanto que no Brasil autoriza-se apenas o segundo tipo de modulação.

Conforme nos mostra a autora (Ibidem: 101), enquanto o governo do Canadá demonstra grande cuidado e preocupação na preservação da língua e da cultura, no Brasil o que se percebe é uma indisposição por parte do Ministério das Comunicações no processo de aprovação de pedidos de autorização para funcionamento e mesmo no dia-a-dia das emissoras haja vista o grande índice de "interferências, lacre e apreensão de equipamentos e perseguição política" (Ibidem: 101) às lideranças de rádios comunitárias. Como se pode observar, sem dúvida, as leis e decretos que regem estas emissoras carecem de uma cuidadosa discussão.

Repensar a aplicabilidade da legislação vigente assim como o papel do jornalista na comunicação comunitária são necessidades imprescindíveis. "A função desse profissional, considerado freqüentemente como agente externo, é provocar a participação" (PAIVA, 2003: 143). Práticas de paternalismo, gestão burocratizante ou autoritarismo técnico e político devem ser combatidas para que o acesso da comunidade à emissora seja efetivo. Quanto maior os níveis de participação, maior também serão os processos educativos e a promoção da cidadania. Como nos salienta a autora, "para ser comunitária é preciso que seja gestão permanente da comunidade. Para ser educativa não basta transmitir aulas e cursos, é preciso uma visão do processo educativo comprometido com a ética e com as mudanças sociais" (Ibidem: 147).

\section{Mídia e cidadania}

Segundo a Declaração Universal dos Direitos Humanos, todas as pessoas têm direito à liberdade de opinião e expressão, o que inclui a liberdade de receber e transmitir informações e idéias. Entendemos que, dessa forma, os meios de comunicação assumem papel decisivo na promoção da cidadania uma vez que "a comunicação implica em informação disseminada que desenvolve a cultura política ou democrática instalada e, em uma consequiência quase necessária e inevitável, realiza a cidadania" (RUBIM, 2003: 100).

Mas, que é cidadania?

Sabemos que a cidadania relaciona-se diretamente ao processo histórico-social. Dessa forma, esta pode ser compreendida de diversas maneiras. Pode relacionar-se ao direito de pertencer a uma nação, igualdade perante a lei, liberdade de ir e vir, liberdade de pensamento, expressão, crenças, etc; pode-se também ligar-se ao direito de participação, de se manifestar e de ser ouvido (PERUZZO, 2002).

Vinculam-se, ainda, à cidadania os direitos civis (séc. XVIII) políticos (séc. XIX), sociais (séc. XX), culturais (séc. XXI). A conquista dos direitos impulsiona-se quando os cidadãos criam a consciência do 
direito de ter direitos, o que, certamente, implica em deveres.

Por uma atualização da noção de cidadania, Rubim salienta que na atual condição social, a existência física apresenta-se como necessária, mas insuficiente para a existência pública. Para o autor, "além da existência física em espaços geográficos torna-se imprescindível, para um ente adquirir existência pública, que ele tenha acesso, que ele circule e mesmo que ele habite cotidianamente o espaço eletrônico em rede" (2003: 110).

Para ele, dessa forma pode ser assegurada a existência pública aos entes sociais. Não com o objetivo de afligir a noção de cidadania nem de abrandar o alento dos utópicos, mas pela grave situação do panorama mundial, o que deduzir quando as estatísticas mostram o quase nulo acesso à internet pelas classes com menor rendimento salarial (IBGE, 2005)? "Com a globalidade a produção do público está associada, mais do que nunca, a existência virtual dos atores sociais em redes eletrônicas mundiais" (RUBIM, loc. cit.). O mesmo é válido para o acesso aos meios de comunicação de massa, mas não apenas na passividade de receptores e sim, também, como emissores.

Desta forma, devido à atual configuração social, talvez devamos pensar em uma nova faceta da cidadania: a digital. Por uma ação dialógica, observa-se que

[...] educadores e comunicadores poderão ver que já não mais trabalham com massa, mas com sujeitos sociais no exercício do conhecimento. A nova ação dialógica dos oprimidos pela exclusão da sociedade informática pode ser a premissa para todos os nossos métodos de alfabetização digital (ALVES, 2003: 215).

Não é sem razão que Paulo Freire aborda a ausência de participação e vivência comunitária do homem brasileiro:

O Brasil nasceu e cresceu sem experiência de diálogo. De cabeça para baixo, com receio da Coroa. Sem imprensa. Sem relações. Sem escolas. Doente. Sem fala autêntica. [...] Entre nós [...] o que predominou foi o mutismo do homem brasileiro. Foi a sua não-participação na solução dos problemas comuns. Faltou-nos, na verdade [...], vivência comunitária (apud MARQUES DE MELO, 2006: 22).

Por fim, ressaltamos que

[...] ser cidadão significa ter os direitos civis respeitados; participar do exercício do poder político; usufruir de um modo de vida digno [...] e ter acesso ao conhecimento, mas também comunicar-se através dos meios tecnológicos que a humanidade desenvolveu e colocou a serviço de todos (PERUZZO, 2002: 85).

Registramos ainda a contribuição da "Carta de São Bernardo"(5). Trata-se de um mapeamento da mídia cidadã brasileira que tem a finalidade de contribuir para a ampliação da cidadania. Para esta pesquisa, a cartografia intelectual de São Bernardo assume premente colaboração quando discute a questão da potencialidade da mídia local no desenvolvimento da cidadania:

A mídia local/regional ocupa papel-chave no desenvolvimento da cidadania, possuindo interfaces com as questões sociais, econômicas, políticas e culturais. Apesar do crescimento e diversidade da mídia local, persiste a reprodução dos padrões da grande mídia nacional/global, com pouco espaço para novos formatos, linguagens e mesmo conteúdos apropriados (apud MARQUES DE MELO, 2006: 32). 
Para tentar entender o processo existente entre mídia e a cidadania na rádio comunitária discutiremos questões acerca da "participação", pois, consideramos que a relação entre participação e cidadania dá-se de forma diretamente proporcional, ou seja, quanto mais efetiva a participação popular nos meios de comunicação maior a possibilidade do exercício da cidadania.

\section{Participação popular}

Para que os alicerces da mídia estejam cravados nos princípios da cidadania e da democracia, entendemos que torna-se imprescindível a participação do cidadão como sujeito e protagonista na comunicação social, efetivando assim, maiores níveis de participação e, por fim, colocando as potencialidades da comunicação a serviço do cidadão.

Tomamos por base os apontamentos de Peruzzo (2004) que utiliza conceitos de vários autores significando o acesso, o tomar parte, o partilhar, os conceitos de co-gestão e de autogestão e engloba em três as diferentes modalidades de participação popular: participação passiva, participação controlada e a participação-poder. Salienta-se que estas podem concretizar-se dialeticamente.

Na participação passiva o indivíduo desenvolve "uma postura de espectador e de conformismo, [...] ele consente, se objetiva, se submete e simplesmente delega o poder a outra" (Ibidem: 78). Aqui o exercício do poder é do tipo autoritário.

Com seu início podendo ser em "decorrência de pressão das próprias bases, como uma conquista, ou ser concedida de cima para baixo", a participação controlada recebe esta denominação por evidenciar algumas restrições à participação popular. "A participação controlada é limitada, ou seja, é favorecida e possível somente nos aspectos ou até o ponto que as instâncias detentoras do poder permitirem. [...] Manipula-se a comunidade para adequar suas demandas aos interesses de quem detém o poder" (Ibidem: 79-80). Por fim, a participação-poder favorece a "participação democrática, ativa e autônoma, propiciando, de modo mais completo, o crescimento das pessoas ou das organizações coletivas enquanto sujeito" (Ibidem: 81). Expressões como co-gestão e autogestão adquirem aqui visibilidade.

A co-gestão implica em co-participação ativa na gestão de uma instituição. Delegam-se parcelas do poder, mas as decisões centrais permanecem sob responsabilidade da cúpula hierárquica.

Já a autogestão refere-se à participação direta da população, no que se refere à tomada de decisões. Supõe-se, então, que o exercício da decisão partilhada requer a existência de "canais desobstruídos, informações abundantes, autonomia, co-responsabilidade e representatividade" (Ibidem: 87).

Os níveis de participação nos meios de comunicação populares ou comunitários também são classificados por Peruzzo (2004: 144) da seguinte forma:

- Mensagens: participação nas entrevistas, depoimentos, denúncias, avisos, etc;

- Produção: participação na produção de notícias, artigos, poesias e desenhos transmitidos pelo meio de comunicação, além da preparação (linha política, objetivos, estrutura, conteúdo), elaboração (textos, roteiros, locução) e edição (seleção, cortes) de materiais midiáticos;

- Planejamento dos meios: participação na política editorial, objetivos, formatação dos programas, gestão, formas de sustentação financeira; 
- Gestão dos meios: participação no processo de administração e controle do veículo.

No contexto sócio-histórico brasileiro observamos que a realização de uma participação efetiva deverá acontecer de modo lento devido a diversos fatores como os valores autoritários difundidos na sociedade e à falta de conscientização política. "Pretender alcançar um grau de participação mais elevado é algo de difícil concretização" (Ibidem: 73). Entretanto, a realização da ampliação da cidadania e da participação na comunicação social nos parece possível. Disto divergem os líderes de conglomerados midiáticos que lutam a qualquer custo para uma ampliação da centralização do poder e do autoritarismo. Ainda assim,

[...] a participação e a comunicação representam uma necessidade no processo de constituição de uma cultura democrática, de ampliação dos direitos de cidadania e da conquista da hegemonia, na construção de uma sociedade que veja o ser humano como força motivadora, propulsora e receptora dos benefícios do desenvolvimento histórico (PERUZZO, 2004: 296).

Através destes conceitos apresentados e de uma observação assistemática de conteúdo tentaremos entender o espaço reservado ao exercício da cidadania na Rádio Jornal FM, através dos níveis e modalidades de participação popular.

\section{A Rádio Jornal FM}

A Associação Cultural Comunitária de Pirajuí(6) foi fundada em 1996. A nosso ver, e conforme depoimento de Américo Pereira, membro da diretoria, a finalidade da criação desta encontra-se desvinculada aos interesses comuns e aos movimentos sociais e comunitários:

A fundação da Rádio Jornal FM aconteceu gradativamente. Primeiro foi fundada a Assoc. Cult. Comunitária de Pirajuí em 1996, quando foi reunido um grupo que constituiu um estatuto social. A partir daí for formada uma diretoria, conselho deliberativo e realizada a primeira reunião registrada em Ata tratando da fundação de uma emissora de rádio.(7)

Através desta fala de Pereira, percebemos que a finalidade principal da criação da Associação era o pedido da concessão de uma Rádio Comunitária. É de conhecimento comum que estas emissoras são concessões feitas pelo Governo Federal e regidas pela Lei 9.612/98.

Atualmente a emissora cumpre uma jornada de 18 horas de programação: Som da Terra: programação musical sertaneja; Conecsom: programação musical e algumas informações de entretenimento; Jornal 105: informações internacionais, nacionais, regionais e locais. Conta com produção local, e áudios de notícias de sítios da internet; Visão Cristã: programa da Igreja Batista Cristã Missionária; Freqüência Máxima: participação do ouvinte no ar com pedidos musicais e notícias de entretenimento; Caravana 105: programação sertaneja; A hora da Ave-Maria: orações católicas; Pau na Máquina: musical.

Veiculam-se ainda boletins informativos de hora em hora com áudios, em sua maioria, retirados do portal da Central de Radiojornalismo, disponível em www.radiojornalismo.com.br.

Ao observarmos a programação desta emissora notamos o predomínio de espaços destinados à música, selecionadas ora por meio de pedidos por carta, telefone, correio eletrônico, ora pela própria equipe responsável pela produção e gestão.

Destacamos ainda o fato de a programação ser muito parecida com a da Pirajuí Rádio Clube(8). A razão estaria ligada a uma tentativa da emissora em disputar uma fatia da audiência local e, principalmente, uma fatia do mercado local. A "Clube" faz parte da comunidade desde a década de 1940, enquanto que a 
Rádio Jornal iniciou efetivamente sua transmissão em 2004.

Endossamos os dizeres de Peruzzo (2006) quando considera que a apropriação do espectro de radiodifusão comunitária por indivíduos e instituições com interesses outros que não os comunitários e sociais gera distorções no seu uso. Mesmo autorizadas a funcionar sob o código legal das comunitárias essas trabalham por interesses particulares, ou seja, não deveriam receber o rótulo de "rádio comunitária".

Os indivíduos e instituições têm o direito de usufruírem das ondas do rádio de baixa potência, seja com finalidades comerciais, políticas e/ou evangelizadoras, mas não no espectro da radiodifusão comunitária. Por que não criar uma legislação específica de rádio local que permita estes outros tipos de emissoras? (Ibidem: 185)

Poderíamos justificar essas distorções nas "limitações de financiamento que levam algumas emissoras a uma maior dependência [do mercado e] do poder público local, com o conseqüente risco de condicionamento de conteúdos" (SILVA, 2007: 167), entretanto, se observarmos a principal finalidade da criação da Associação perceberemos o escopo da centralização da gestão e produção. A gestão desta emissora restringe-se à cúpula organizacional, aos poucos funcionários e aos interessados e possibilitados em adquirir um horário na programação.

Por vezes, a emissora estabelece contratos com locutores interessados em participar na programação. Todo o lucro angariado através dos anúncios publicitários para o programa é destinado aos locutores e uma quantia fixa é repassada à diretoria da Associação.

Nesta perspectiva, distancia-se da potencialidade de uma "rádio comunitária" proporcionar a democratização da informação, a participação, o exercício da cidadania e a educação informal e nãoformal $(9)$.

A emissora, que transmite a um raio maior que o autorizado pela legislação, disponibiliza um portal na internet com um histórico, músicas mais tocadas, promoções, publicidade, canal para participação através do "Mural de recados", enquetes, programação, galeria de fotos e um recurso que possibilita ao internauta ouvir conteúdos através da internet(10).

Além da ausência do termo comunitário ou comunidade, seja no nome fantasia da emissora, seja no texto de apresentação, o site chegou a disponibilizar o link "Anuncie aqui":

Nossa emissora tem grande dimensão no território regional, com abrangência em diversas cidades que compõe nossa região. Fazendo sua publicidade aqui seu trabalho e esforço será levado a que possa desconhecer seus trabalhos.

Desenvolvemos e produzimos todos os estilos de spots, comerciais, jingles para qualquer tipo de comércio ou instituição que seja.<smiles>[AlH2]</smiles>

Será uma satisfação ter você como cliente!(11)

Após uma reformulação no site a emissora retirou este link do ar.

Resta-nos apontar para a configuração desta rádio comunitária como uma microempresa, característica de 
veículos que

Operam o sistema de som enquanto meio para veiculação de anúncios e outras formas de patrocínio visando o lucro particular. Claro que acabam prestando algum serviço de utilidade para o local, chegando às vezes até mesmo a transmitir notícias das associações de moradores (PERUZZO, 1998: 6).

Desta forma, a emissora não se configura como mídia contra-hegemônica porque veicula conteúdos parecidos com o da grande mídia e, em alguns casos, a tem como fonte principal de informação.

\section{Considerações}

Consideramos, a partir deste caso, que as rádios comunitárias, por sua proximidade territorial, configuram-se como um espaço em potencial para o desenvolvimento da participação popular nos meios de comunicação e, por consequiência da cidadania. Entretanto, devido a algumas distorções na prática da rádio comunitária como comprometimentos políticos, econômicos e limitações tecnológicas e profissionais, estes espaços tornam-se cada vez mais escassos, a participação passa a ser limitada aos interesses destes "coronéis da mídia" que monopolizam até mesmo o espectro das rádios comunitárias e o processo de mobilização e motivação para o exercício da cidadania acaba desvinculado.

Neste caso, as modalidades de participação predominantes são o telefonema, as cartas, além de um diferencial que a mídia local proporciona: trata-se da participação através da presença física da população que sabe onde o veículo de comunicação está instalado e, na maioria das vezes, conhece os profissionais envolvidos. Observa-se que a rádio comunitária, apesar das limitações acima citadas, proporciona um nível maior de participação em comparação à grande mídia. Em contrapartida, se compararmos estes aos níveis ideais para o desenvolvimento do exercício da cidadania, perceberemos a necessidade de uma outra comunicação, comunitária e dialógica.

\section{Bibliografia:}

ALUMUKU, P.; WHITE, R. Rádio Comunitária para o Desenvolvimento na África. In: Anuário Internacional de Comunicação Lusófona. vol. 3, n. 1. 2005. p. 56-65.

ALVES, Luiz Roberto. Cidade, Comunicação e Desenvolvimento Local. In: PERUZZO, C.M.K.; ALMEIDA, F. F. de (org.). Comunicação para a Cidadania. São Paulo: Intercom/Uneb, 2003. p. 203218.

IBGE - Instituto Brasileiro de Geografia e Estatística. Documento eletrônico. Disponível em . Acesso em 10 ago.2007.

LÓPEZ VIGIL, J. I. Manual urgente para radialistas apaixonados. 2 ed. São Paulo: Paulinas, 2004.

MARQUES DE MELO, José. Mídia Cidadã: Utopia Brasileira. São Bernardo do Campo: Universidade Metodista de São Paulo, 2006.

PAIVA, R. Para reinterpretar a Comunicação Comunitária. In: PAIVA, R. O retorno da comunidade: os novos caminhos do social. Rio de Janeiro: Mauad X, 2007. p. 133-148.

O espírito comum: Comunidades, Mídia e Globalismo. 2 ed. Rio de Janeiro: Mauad X, 
2003.

PERUZZO, Cicilia Maria K. Participação nas rádios comunitárias no Brasil. Versão ampliada de Paper apresentado no GT Cultura e Comunicação Popular, XXI Congresso Brasileiro de Ciências da Comunicação, Recife/PE, 9 a 14/09 de 1998. Disponível em: . Acesso em: 10 ago. 2007.

Ética, liberdade de imprensa, democracia e cidadania. In: Palestra proferida no III Encuentro Nacional de Investigadores de la Comunicación. Bolívia, Santa Cruz de la Sierra, junho de 2002.

Comunicação nos movimentos populares: a participação na construção da cidadania. 3 ed.

Petrópolis: Vozes, 2004.

Rádios Comunitárias: entre controvérsias, legalidade e repressão. In: MARQUES DE MELO, J.; GOBBI, M. C.; SATHLER, L (org.). Mídia Cidadã: Utopia Brasileira. São Bernardo do Campo: Universidade Metodista de São Paulo, 2006. p. 183-192.

Rádio Comunitária, Educomunicação e Desenvolvimento. In: PAIVA, Raquel. O retorno da comunidade: os novos caminhos do social. Rio de Janeiro: Mauad X, 2007. p. 69-94.

RUBIM, A. A. C. Cidadania, Comunicação e Cultura. In: PERUZZO, C.M.K.; ALMEIDA, F. F. de (org.). Comunicação para a Cidadania. São Paulo: Intercom/Uneb, 2003. p. 100-114.

SILVA, Maria Terezinha da. Gestão e mediações nas rádios comunitárias: um diagnóstico do Estado de Santa Catarina. In: Revista Brasileira de Ciências da Comunicação. São Paulo: Paulus, v.30, n. I, jan-jun 2007. p. 151-173.

VENTURA, G. C. Rádios Comunitárias: análise comparativa entre Brasil e Canadá. In: Revista interfaces Brasil/Canadá. Rio Grande, n. 4, 2004. Disponível em: . Acesso em: fev. 2008. p. 91-102.

\section{Notas:}

(1) Paper apresentado no XII Colóquio Internacional sobre a Escola Latino-Americana de Comunicação CELACOM, promovido na Universidade Metodista de São Paulo/Cátedra Unesco, de 5 a 7 de maio de 2008.

(2) Sobre Cidadania ver p. 6.

(3) Sobre liberdade de comunicação e cidadania ver PERUZZO, Cicília M. K. "Ética, liberdade de imprensa, democracia e cidadania”. In: III Encontro Nacional de Investigadores de la Comunicación. Bolivia, Santa Cruz de la Sierra, junho de 2002.

(4) Ver as características da mídia comunitária em PERUZZO, Cicília M. Krohling. "Mídia Comunitária". In: Revista Comunicação e Sociedade. n. 32. São Bernardo do Campo: UMESP, 1998 e em PERUZZO, Cicília M. K. "Mídia Local e suas interfaces com a mídia comunitária". In: Anuário Internacional de Comunicação Lusófona. v. 4, n. 1, 2006.

(5) Convocados pela Cátedra UNESCO/METODISTA de Comunicação e pela World Association for Christian Communication (WACC - América Latina), pesquisadores e ativistas de Comunicação Social 
de todo país reuniram-se na Universidade Metodista de São Paulo, em São Bernardo do Campo, em 2005, para avaliar o Mapa Brasileiro da Mídia Cidadã. Como um dos frutos deste Seminário publicou-se Mídia Cidadã: Utopia Brasileira (2006).

(6) A emissora localiza-se na cidade de Pirajuí, interior do estado de São Paulo.

(7) Entrevista concedida ao autor em 25 ago.2007, via correio eletrônico.

(8) Uma outra emissora da cidade que opera em frequiência AM. É ligada à Rede Católica de Rádios. Sobre a programação desta emissora ver artigo de nossa autoria: "Participação e cidadania na mídia local: o caso de Pirajuí/SP”. In: Inovcom - Revista Brasileira de Inovação Científica em Comunicação. v. $2, n$. 2 http://revcom2.portcom.intercom.org.br/index.php/inovcom/article/view/4849/4546

(9) Sobre processos de educação não-formal e informal nas rádios comunitárias ver: Rádio Comunitária, educomunicação e educação ambiental. Paper de nossa autoria, apresentado no GT - Mediações e Interfaces Comunicacionais, do Inovcom, evento componente do XIII Congresso de Ciências da Comunicação na Região Sudeste. São Paulo. 07 a 10 de maio de 2008.

(10) Sobre as formas de ocupação do espaço na rede pelas rádios comunitárias ver PERUZZO, Cicília M. Krohling. "Rádio Comunitária na Internet: empoderamento social das tecnologias". In: Revista Famecos. $n^{o}$. 30, Porto Alegre, 2006.

(11) Disponível em: www.radiojornalpirajui.com.br

\section{Mini Currículo :}

Marcelo de Oliveira Volpato é jornalista pela Universidade de Marília. Mestrando em Comunicação Social pela Universidade Metodista de São Paulo - UMESP. Bolsista CNPq. 